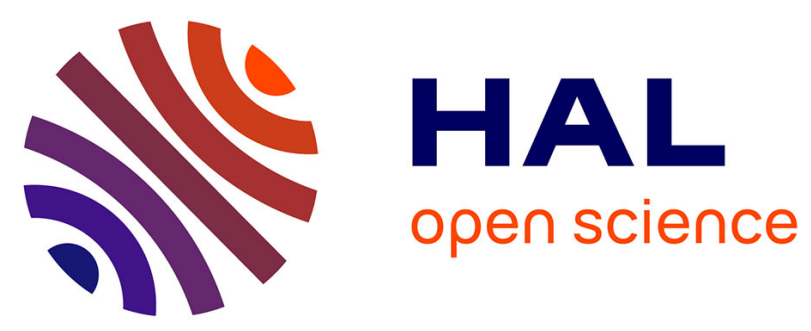

\title{
When Fit Fosters Favoring: The Role of Private Self-Focus
}

\author{
Marieke L. Fransen, Bob M. Fennis, Ad Th. H. Pruyn, Kathleen D. Vohs
}

\section{To cite this version:}

Marieke L. Fransen, Bob M. Fennis, Ad Th. H. Pruyn, Kathleen D. Vohs. When Fit Fosters Favoring: The Role of Private Self-Focus. Journal of Experimental Social Psychology, 2010, 47 (1), pp.202. 10.1016/j.jesp.2010.09.004 . hal-00918799

\section{HAL Id: hal-00918799 \\ https://hal.science/hal-00918799}

Submitted on 15 Dec 2013

HAL is a multi-disciplinary open access archive for the deposit and dissemination of scientific research documents, whether they are published or not. The documents may come from teaching and research institutions in France or abroad, or from public or private research centers.
L'archive ouverte pluridisciplinaire HAL, est destinée au dépôt et à la diffusion de documents scientifiques de niveau recherche, publiés ou non, émanant des établissements d'enseignement et de recherche français ou étrangers, des laboratoires publics ou privés. 


\section{Accepted Manuscript}

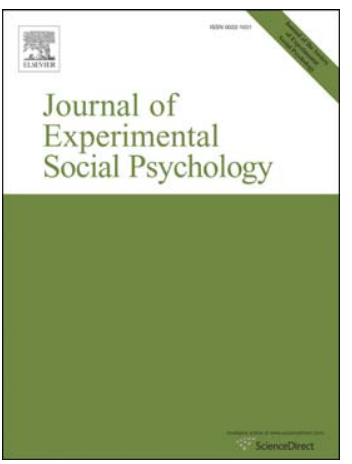

PII:

S0022-1031(10)00210-6

Reference:

do1: 10.1016/j.jesp.2010.09.004

YJESP 2536

To appear in: Journal of Experimental Social Psychology

Received date: 22 February 2010

Revised date: $\quad 26$ August 2010

Please cite this article as: Fransen, M.L., Fennis, B.M., Pruyn, A.T.H. \& Vohs, K.D., When Fit Fosters Favoring: The Role of Private Self-Focus, Journal of Experimental Social Psychology (2010), doi: 10.1016/j.jesp.2010.09.004

This is a PDF file of an unedited manuscript that has been accepted for publication. As a service to our customers we are providing this early version of the manuscript. The manuscript will undergo copyediting, typesetting, and review of the resulting proof before it is published in its final form. Please note that during the production process errors may be discovered which could affect the content, and all legal disclaimers that apply to the journal pertain. 


\title{
Running head: PRIVATE SELF-FOCUS AND REGULATORY FIT
}

When Fit Fosters Favoring: The Role of Private Self-Focus

Marieke L. Fransen

University of Amsterdam

Bob M. Fennis

University of Groningen

Ad Th. H. Pruyn

University of Twente

Kathleen D. Vohs

University of Minnesota

Please send correspondence to: Marieke L. Fransen, Amsterdam School of Communication Research, University of Amsterdam, Kloveniersburgwal 48, 1012 CX Amsterdam, The Netherlands. Phone: 003120 2522110, Email: m.l.fransen@uva.nl

Keywords: regulatory focus, regulatory fit, private self-focus, persuasion, compliance

\begin{abstract}
The present research extends work on the 'the value from fit' principle by showing that regulatory fit effects on persuasion and behavioral compliance are stronger for people high, as opposed to low, in private self-focus. Previous research has shown that people high in private self-focus are strongly affected by external information. In the current work, we demonstrated that people high (versus low) in private self-focus are more persuaded by information that matches (versus mismatches) activated self-knowledge.
\end{abstract}




\section{When Fit Fosters Favoring: The Role of Private Self-Focus}

The past two decades have seen an explosion of work on the role of regulatory fit in behavioral compliance, preference formation, attitude change, and persuasion (e.g., Cesario, Grant, \& Higgins, 2004; Florack \& Scarabis 2006; Lee \& Aaker, 2004). This work consistently shows that framing a persuasive message in congruence with consumers' regulatory focus enhances persuasion, and promotes compliance. Although recent studies have targeted underlying mechanisms that may explain why regulatory fit fosters persuasion (e.g., Hong \& Lee, 2008; Lee \& Aaker, 2004; Wang \& Lee, 2006), it remains unclear under which circumstances regulatory fit effects are likely to occur. In social science, it is almost certainly never the case that an effect happens across all situations and for all people. Hence, it is important to ask what individual characteristics or particular circumstances alter the persuasiveness of regulatory fit and why.

Departing from prior research, we propose and demonstrate in the present research that regulatory fit effects on persuasion are stronger for people with high private self-focus because these people are especially affected by external information that is relevant for the self (Hull, Meteyer, \& Matthews, 2002). Private self-focus increases the activation of selfknowledge, thereby boosting the impact of information that fits or misfits with one's activated self-knowledge (i.e., regulatory focus).

\section{Regulatory Fit}

Regulatory Focus Theory (Higgins, 1997) proposes that there are two distinct mechanisms that regulate judgments and behavior, labeled promotion and prevention focus. When people are concerned with their ideal self, they are said to adopt a promotion focus. This focus prompts an eager strategy in the pursuit of hopes, wishes, and aspirations. People with a promotion focus are especially sensitive to the presence or absence of positive outcomes. In contrast, when people are concerned with their ought self, they are said to adopt 
a prevention focus, which entails vigilant strategies to fulfill duties, obligations, and responsibilities. A prevention focus is concerned with the presence or absence of negative outcomes. These self-regulatory strategies are independent of each other and can coexist simultaneously. A promotion or prevention focus can be momentarily activated by situational factors (Idson, Liberman, \& Higgins, 2000), and people tend to have a chronic predominant orientation focus on which they rely in most situations (e.g., Higgins, 2002).

Research suggests that people in a promotion orientation are especially focused on information relating to the achievement of success (i.e., positive outcomes), whereas those in a prevention orientation are focused on avoiding failure (i.e., negative outcomes; Higgins \& Tykocinski, 1992). People with a promotion focus are more motivated and perform better when they use eager goal pursuit strategies aimed at positive outcomes whereas people with a prevention focus are more motivated and perform better when they use vigilant goal pursuit strategies aimed at preventing negative outcomes (Forster, Higgins, \& Idson, 1998; Shah, Higgins, \& Friedman, 1998). These results are in line with the principle that Higgins (2000) has termed 'value from fit' (see also Avnet \& Higgins, 2006; Higgins, 2002; 2005). This principle holds that people experience regulatory fit when they use goal pursuit strategies that match their (current) focus orientation, which in turn increases the perceived value of their behavior.

The previous findings are relevant to attitude change and persuasion because messages advocating values or viewpoints can focus on either the negative outcomes that could happen by not acting upon the message or the positive outcomes that could happen by complying with the message. Emphasizing negative outcomes that can be averted fits with a prevention oriented state whereas stressing positive outcomes that can be achieved fits with a promotion focus. 
Indeed, previous research has established that people are more persuaded when outcomes are framed so that they align with people's current regulatory focus as compared to outcomes that are not framed in alignment with people's regulatory focus (e.g., Cesario, Grant et al., 2004, Study 2; Florack \& Scarabis, 2006; Lee \& Aaker, 2004). However, we maintain that these effects of regulatory fit are a function of individuals' self-focus.

\section{Relating regulatory fit and private self-focus}

Recent research by Hull et al., (2002) shows that people with high (versus low) private self-focus are more influenced by external information because private self-focus increases sensitivity and responsiveness to those aspects of the environment that are relevant to the self. General theories on self-awareness (e.g., Duval \& Wicklund, 1972) state that people have the ability to focus their attention on objects and events in the external environment or on themselves (i.e., self-focus), and that people can and do switch between these spheres. It is generally agreed that the process of focusing on one's self has a public and a private dimension (e.g., Fenigstein, Sheier, \& Buss, 1975; Franzoi \& Brewer, 1984). Public self-focus is characterized by the awareness of oneself from the imagined perspective of others whereas private self-focus is characterized by attentiveness to one's inner states, personal history, and specific features of the self. People with high private self-focus think frequently about themselves, scrutinize their behavior, and reflect on their thoughts. Moreover, people high in private self-focus are quick to make self-descriptive statements and are sensitive to changes in their internal state (Mueller, 1982; Scheier, Carver, \& Gibbons, 1979). In contrast, people with low private self-focus are less likely to scrutinize or be sensitive to their personal motives or states. Private self-focus can be activated by situational demands but is also a dispositional characteristic of individuals.

Theories on private self-focus suggest that attention to the internal, personal aspect of one's self results in self-evaluation (e.g., Duval \& Wicklund, 1972; Scheier \& Carver, 1983). 
Such self-evaluation is expected to instigate a self-regulatory process aimed at reducing discrepancies between one's current state and an internal norm or standard. From this perspective one could assume that people with high (versus low) private self-focus are less prone to external information because they are focused on their internal norms and values. Yet Hull and colleagues (Hull \& Levy, 1979; Hull, Treuren, Ashford, Propsom, Andrus, 1988; Hull et al., 2002) forwarded a different perspective by emphasizing the role of information processing under conditions of high private self-focus. These authors propose that private self-focus relates to the encoding of information in terms of its self-relevance. According to this theorizing, a state of high private self-focus enhances the processing of self-relevant stimuli by activating knowledge about the self (Geller \& Shaver, 1976).

Germane to the current research, Hull et al. (2002) found that the behavior of people high in private self-focus is more influenced by external primes than is the behavior of people low in private self-focus. Hull et al. (2002; experiment 3) showed that high private selffocused participants performed better on a cognitive task after an implicit success prime but worse on the same task when given an implicit failure prime, whereas the performance of people low in private self-focus was unaffected by the primes. These effects suggest that people high in private self-focus are prone to encode external information as self-relevant.

In accordance with these findings, we start with the notion that high private self-focus renders people susceptible to external information. Yet it would not be adaptive for people to walk around open, porous, and readily influenced by any and all environmental information; hence, we argue that not all information is considered self-relevant for people high in private self-focus. Rather, we propose that people high in private self-focus will particularly mark external information that fits with previously stored or activated self-knowledge (e.g., one's regulatory focus) as relevant. When the activated self-knowledge, instigated by a state of high private self-focus, fits with incoming information it will have a greater impact than when 
there is no fit. Translated into the current research this would imply that, in contrast to low self-focused people, appeals framed in promotion terms will be readily perceived as selfrelevant to high self-focused people with a promotion focus and appeals framed in prevention terms will be readily perceived as self-relevant to high self-focused people with a prevention focus. Hence, we hypothesized that the effect of regulatory fit on persuasion is moderated by private self-focus. High private self-focused people (dispositional and situational) will be more affected by information that is congruent (versus incongruent) with their regulatory focus than will people with low private self-focus. We tested our notions in two experiments.

\section{Experiment 1}

Experiment 1 was designed as a first test to assess whether people are more persuaded by a message that fits their regulatory focus than when a message does not fit their regulatory focus and to test the moderating role of private self-focus. More in particular, we hypothesized that these effects would be stronger for participants with dispositionally high (versus low) private self-focus because these participants were expected to be highly affected by external self-relevant information (i.e., information that fits with their current orientation focus).

\section{Design and Participants}

The experiment used a 2 (regulatory focus: promotion vs. prevention) x 2 (message framing: promotion-framed vs. prevention-framed) x 2 (private self-focus: high vs. low) between-subjects design. One hundred thirty-one college students (41 female) with a mean age of 22 years $(S D=3.08)$ participated in exchange for 6 Euros or partial course credit.

\section{Procedure}

Participants were told that the experiment consisted of several unrelated parts. After responding to demographic questions, dispositional private self-focus was measured and either a promotion or prevention focus was induced by exposing them to promotion-based 
advertising slogans or prevention-based advertising slogans, respectively. Subsequently, participants were asked whether they would be willing to help a charity that expressed either prevention-related or promotion-related values in their message.

\section{Independent Variables}

Private self-focus. Private self-focus was measured using the Private Self-

Consciousness scale originally developed by Fenigstein et al. (1975; Vleeming \& Engelse, 1981). This scale measures stable individual differences in private self-focus. Participants rated a total of 10 statements (e.g., 'I reflect on myself a lot' and 'I'm generally attentive to my inner feelings') on a five-point Likert scale ( $1=$ extremely uncharacteristic, $5=$ extremely characteristic). To obtain an index of dispositional private self-focus, we averaged the scores on the items $(\alpha=.74)$ and used the median (3.4) to classify participants either as high or low in private self-focus.

Regulatory focus. Situational regulatory focus was activated by exposing participants to four brand logos of different product categories (i.e., cars, clothing, facial cosmetics, and airlines). These four logos were accompanied by either promotion-based slogans (i.e., 'Its Your Goal!', 'Fits Your Ambition', 'Retains Your Youth', 'Straight to your Dreams') or prevention-based slogans (i.e., 'Your Safety is Our Priority', 'Fits your Responsibility' 'Prevents Aging', 'Smooth \& Safe'; for a similar procedure see Aaker \& Lee, 2001; Fransen, Fennis, \& Pruyn, 2007). During exposure, participants were asked to provide their opinion on three statements regarding the brand logos and the slogans (e.g., 'the slogan is well formulated') in order to keep their attention on the brands. No time limit was given.

A pretest was conducted to test whether the slogans activated the corresponding regulatory focus. Participants $(\mathrm{N}=36)$ were exposed to the advertising slogans, described above, and subsequently responded to three different items, which were labeled as 'personal choices' (Pham \& Avnet, 2004). Participants were asked to choose one of two statements that 
anchored opposite ends of seven-point scales. The items started with 'I would prefer to...' Participants indicated which option they would prefer to perform at this moment in time (e.g., 'take a trip around the world' vs. 'pay back my loans'). Participants' mean ratings were used as an index of regulatory focus ranging from 1 (emphasis on ideals) to 7 (emphasis on oughts). Hence, higher scores indicate a stronger prevention focus and lower scores indicate a stronger promotion focus. As expected, participants who were exposed to the preventionbased advertising slogans scored higher on this measure $(M=3.06, S D=0.84)$, indicating a relative emphasis on oughts compared to participants who saw the promotion-based slogans $(M=2.44, S D=.34, F(1,34)=8.0, p<.01)$.

Message framing. Participants were instructed to read the description of an existing but unfamiliar charitable organization (G.S.A.P.; General Society for African Projects) that expressed its goals either in eager terms, aimed at realizing desirable outcomes (e.g., 'Our main aim is to make sure that children can go to school so they can learn how to read and thus realize their ambition and dreams'), or in vigilant terms, aimed at avoiding failure (e.g., 'Our main aim is to make sure that children can go to school so we can prevent illiteracy and a lack of education and thus forestall unemployment'). Participants were randomly assigned to the promotion-framed or prevention-framed information.

\section{Dependent Variable}

To measure compliance with the request to support the charity, participants were asked whether they would 1) like to receive more information about the charity, 2) leave their email address so they could be contacted when the charity needed help in the future and 3) be willing to help the charity by distributing flyers. Agreement with each of these requests was scored $(0=$ no, $1=$ yes $)$ and summed to arrive at an overall index of compliance $(\alpha=.82)$. 
We expected that participants would offer more help to a charity whose values were stated in a manner that corresponded with their current orientation state and that this interaction effect would be moderated by participants' private self-focus. An analysis of variance (ANOVA) revealed a significant interaction effect between regulatory focus and message framing $\left(F(1,123)=10.12, p<.01, \eta_{p}{ }^{2}=.08\right)$. The means showed that participants in the promotion focus condition showed more compliance when the charity was framed in promotion-related values $(M=.55, S D=1.06)$ than when it was framed in prevention-related values $(M=.15, S D=.62)$. In contrast, participants in the prevention focus condition showed more compliance when it was framed in prevention-related values $(M=.32, S D=.84)$ rather than promotion-related values $(M=.06, S D=.35)$.

Moreover, the results yielded the predicted three-way interaction among regulatory focus, message framing, and private self-focus $\left(F(1,123)=5.20, p<.05, \eta_{p}{ }^{2}=.04\right)$, indicating that the interaction between regulatory focus and charity framing was more pronounced for participants with high private self-focus than for participants low in private self-focus ${ }^{1}$. In line with expectations, the two-way interaction between regulatory focus and message framing was significant for participants high in private self-focus $(F(1,64)=10.20$, $\left.p=.002, \eta_{p}{ }^{2}=.14\right)$ but was not significant for participants low in private self-focus $(F<1)$. To probe the two-way interaction effects for high vs. low private self-focus participants, a series of simple main effect analyses were conducted. Results indicated that among

\footnotetext{
${ }^{1}$ For reasons of readability, median splits are reported throughout the two studies. However, please note that multiple regression analysis with private self-focus as a continuous predictor (centered), regulatory focus and message focus as dichotomous predictors (dummy-coded), and interaction terms reflecting the two-way interaction between regulatory focus and charity framing, and the three-way interaction between regulatory focus, charity framing and private self-focus, yielded similar significant results (two-way interaction: $\beta=.49, p<$ .001 ; three-way interaction: $\beta=.24, p<.05)$.
} 
participants high in private self-focus, a situationally-activated promotion focus resulted in more compliance with the promotion-framed charity message $(M=.60, S D=1.10)$ than with the prevention-framed charity message $\left(M=.10, S D=45 ; F(1,123)=5.98, p<.05, \eta_{p}{ }^{2}=\right.$ .05). Conversely, participants high in private self-focus with a situational prevention focus were more compliant in response to a prevention-framed charity message $(M=.83, S D=$ 1.11) than to a promotion-framed charity message $(M=.06, S D=.25),(F(1,123)=9.74, p<$ $\left..01, \eta_{p}{ }^{2}=.07\right)$. In contrast, for participants with low private self-focus, fit versus nonfit between situationally-activated focus orientation and message framing did not affect compliance rates (both $F$ s $<1$, figure 1).

$<<<$ Insert Figure 1 about here $>>$

The present findings provide a first empirical demonstration of our hypothesis that private self-focus moderates the effects of outcome-based regulatory fit. High private selffocused individuals were more affected by external messages that fit with their regulatory focus than were low private self-focused individuals. These results offer initial support for the notion that the focus on one's private self activates self-knowledge (i.e., one's regulatory orientation), which renders information that matches with this knowledge highly influential. The next experiment extends these findings to overt behavior, rather than behavioral intentions.

\section{Experiment 2}

The aim of this experiment was to extend the findings of the first experiment in several ways. First, we focused on actual monetary donations as the dependent variable, rather than behavioral intentions. Actual behavior is too seldom the focus of psychological experiments, in part because it is difficult to pin down (Baumeister, Vohs, \& Funder, 2007). Hence, to obtain results on a measure of behavior indicates that the hypothesized effect is 
robust and reliable. Second, the present experiment measured participants' trait regulatory focus rather than the state manipulation of regulatory focus that was employed in the first experiment. This change goes toward construct validity by attempting to find converging evidence using state manipulations as well as trait assessments. Third, a private self-focus manipulation was used to establish that the previously found results also hold when private self-focus is momentarily induced.

\section{Design and Participants}

Our predictions were tested in a 2 (regulatory focus: promotion vs. prevention) x 2 (message framing: promotion-framed vs. prevention-framed) x 2 (private self-focus: high vs. low) design with regulatory focus and private self-focus as between subjects variables and message framing as a within subjects variable. Fifty-three undergraduate students (26 females; $\left.M_{\text {age }}=20.94, S D_{\text {age }}=2.80\right)$ participated in exchange for partial course credit and 6 Euros.

\section{Procedure}

Upon arrival at the laboratory participants were told that the experiment consisted of several unrelated parts. They responded to demographic questions, after which their predominant regulatory focus was measured. Subsequently, private self-focus was manipulated and participants read messages about two charities. One of the charities was framed in promotion-related terms and the other in prevention-related terms. Finally, participants were asked if they would like to donate money to either one or both charities. After data collection was complete, the money raised during the experiment was donated to the charities.

\section{Independent Variables}

Private self-focus. To activate situational private self-focus, we used a procedure developed and validated by Fenigstein and Levine (1984). Participants in the high private 
self-focus condition were instructed to write a story using the following words (target words italicized here): 'I', 'this morning', 'park', 'candy', 'myself', 'walking', 'lamp', 'forgetting', 'me', 'throwing', 'solve', 'glove', 'case', 'shampoo', 'my', 'never', 'face', 'alarm clock', 'alone', 'bike'. In the low private self-focus condition the target words were replaced by the words 'he', 'himself', 'his', 'him', and 'together'.

Regulatory focus. We used the Regulatory Focus Questionnaire (Higgins et al., 2001), which is comprised of six promotion-items and five prevention items to establish participants predominant focus. Participants indicated on 5-point scales how frequently specific events had occurred in their lives (ranging from 'never or seldom' to 'very often'). The reliability of the promotion construct was satisfactory $(\alpha=.66)$. The original prevention items did not reach a satisfactory reliability level $(\alpha=.55)$. Based on a factor and reliability analysis, we decided to drop one of the prevention items ('not being careful enough has gotten me into troubles at times') thereby increasing Cronbach's alpha to .63. A factor analysis with the remaining items resulted in the two expected constructs (eigenvalue promotion $=2.34$, eigenvalue prevention $=2.0$ ). Further, Pearsons' Correlation between the two constructs was not significant $(r=.028, p=.84)$, indicating that the two factors, as expected, reflect distinct constructs. A procedure developed by Cesario et al. (2004) subsequently assessed whether participants were predominantly promotion- or prevention-focused. To this end, difference scores were calculated between the mean scores on the promotion items and prevention items, with the resulting median score (.33) used to classify participants as either predominantly promotion or prevention-focused.

Message framing. Participants were informed that a group of researchers were supporting two different charities, G.S.A.P (the same organization as used in the previous experiment) and Nepal Pariwar, and that they were looking for donators. (Both charities exist and have the goal to stimulate educational programs in third world countries.) 
One of the charities was framed in promotion-related terms whereas the other charity was framed in prevention-related terms. The framing of the charities was randomized; half of the participants read the information about G.S.A.P. in a promotion frame (e.g., 'Our main aim is to make sure that children can go to school so they can learn how to read and thus realize their ambition and dreams') and the information about Nepal Pariwar in a prevention frame (e.g., 'Our main aim is to make sure that children don't have to go to school in an unhygienic and unsafe environment'), and vice versa.

\section{Dependent Variable}

After reading the persuasive messages, participants were asked whether they wanted to donate any part of their participation renumeration to one or both charities. Participants were free to donate whatever amount they wanted (as well as none at all). The amount of money donated to either charities served as the dependent measure.

\section{Results and Discussion}

We tested two main hypotheses. First, that participants would donate more money to a charity that was framed in terms that corresponded to their dispositional regulatory focus than a charity that was framed in a manner that mismatched their regulatory focus. Second, that this effect would be moderated by situational private self-focus. Hence, a 2 (regulatory focus: promotion vs. prevention) x 2 (message framing: promotion-framed vs. prevention-framed) $\mathrm{x}$ 2 (private self-focus: high vs. low) ANOVA with repeated measures on the second factor was conducted. Order of presentation of the charities was also included as an independent variable to control for any potential confounding effects. As expected, we found an interaction effect between regulatory focus and charity framing $\left(F(1,45)=6.26, p<.05, \eta_{p}{ }^{2}=.12\right)$. Participants with a predominant promotion focus donated 1.68 Euro $(S D=1.51)$ to the promotion framed charity (approximately $\$ 2.13$ ) and 1.13 Euro $(S D=1.22)$ to the prevention framed charity (approximately $\$ 1.43$ ). Conversely, participants with a predominant prevention focus donated 
1.55 Euro $(S D=1.69)$ to the prevention framed charity (approximately $\$ 1.96)$ and 1.07 Euro $(S D=1.26)$ to the promotion framed charity (approximately $\$ 1.35)$.

In line with predictions, a significant three-way interaction between regulatory focus, charity framing, and private self-focus qualified the two-way interaction $(F(1,45)=6.78, p<$ $.05, \eta_{p}{ }^{2}=.13$ ). Replicating the results of experiment 1 , the two-way interaction between regulatory focus and message framing was significant only for participants high in private self-focus $\left(F(1,23)=7.79, p=.01, \eta_{p}{ }^{2}=.25\right)$, and not for participants low in private selffocus $(F<1)$. Additional simple main effect analyses confirmed that for participants high in self-focus, a predominant promotion focus elicited higher monetary donations to a promotion framed charity $(M=1.91, S D=1.69)$ than to a prevention framed charity $(M=.1 .02, S D=$ 1.16), $\left(F(1,45)=4.96, p<.05, \eta_{p}{ }^{2}=.09\right)$. Conversely, high private self-focus participants with a predominant prevention focus donated more money to the charity when it was framed in prevention terms $(M=1.88, S D=2.03)$ rather than promotion terms $(M=.65, S D=1.09)$, $\left(F(1,45)=8.63, p<.01, \eta_{p}^{2}=.16\right)$. In contrast, regulatory fit did not affect charitable behavior among participants with low private self-focus, both $F_{\mathrm{s}}<1$ (figure 2). No significant main effect or interaction effects with order of charity presentation was observed (all $p \mathrm{~s}>.15$ )

$\ll<$ Insert Figure 2 about here $>>$

The findings of this experiment corroborate and extend the results of the first experiment by showing that people donate more (real) money to a charity when its message is framed in terms that are congruent (versus incongruent) with their dispositional orientation focus, and that this effect is contingent on a private self-focus state. Moreover, the results generalized to a situation in which participants' private self-focus was manipulated instead of measured. In addition, the predicted effects are observed regardless of whether regulatory 
focus was situationally manipulated (as in experiment 1) or measured as a chronic trait (as in the current experiment).

\section{General Discussion}

Our main objective with the present experiments was to delineate when regulatory fit results in increased persuasion and behavioral compliance and when it does not. In two experiments, we found support for the hypothesis that effects of regulatory fit on persuasion and behavior occurred among people with high private self-focus and was absent among those with low private self-focus. Specifically, we found that participants high in private self-focus with a promotion focus were more willing to help (experiment 1) and donate to charity (experiment 2) when the charity's message was described in eager terms (aimed at attaining positive outcomes) rather than vigilant terms (aimed at preventing negative outcomes). The opposite was found among people high in private self-focus with a prevention focus; they were more persuaded when the message was described in vigilant terms.

Whereas previous research has shown effects of regulatory fit on preferences, attitudes, persuasion, and memory, the present experiments are the first to show actual (donating) behavior as a function of outcome-based regulatory fit (cf. Baumeister et al., 2007). People donated more money to a charity that was framed in such a way that it fit their regulatory focus than when the charity was framed in a nonfit manner.

Notably, the present experiments are the first to reveal the moderating role of private self-focus in regulatory fit effects. We found that the effects of regulatory fit on persuasion were stronger among people with high private self-focus compared to people with low private self-focus. The effect of private self-focus was so powerful that we observed no effect of regulatory fit on persuasion among participants in a state of low private self-focus (although 
aggregating over different levels of private self focus still showed the effects of fit on persuasion in line with previous research).

The current results should be viewed through the lens of their potential strengths and drawbacks. Toward the strength side, we used validated and established procedures to manipulate regulatory focus (Experiment 1) and private self-focus (Experiment 2), which increases confidence in our findings although we acknowledge that the experiments did not adopt manipulation checks for the procedures. Also, that we observed similar results using measures of dispositional preferences for behaving as well as situational manipulations speaks to the robustness of the observed effects. There is a potential concern that both experiments were conducted in the domain of charity behavior, which might limit the generalizability of our results. One could argue, for instance, that a high private self-focus might amplify the use of active self-relevant information (i.e., one's regulatory focus) particularly for decisions and judgments that are less self-relevant. Further research could examine this possibility by including situations in which the benefits are to a greater and lesser extent relevant to the self.

\section{Self-Relevant Processing Theories}

The present results are in line with the work by Hull and colleagues (Hull \& Levy, 1979; Hull et al., 1988; Hull et al., 2002) in suggesting that people high in private self-focus are highly influenced and affected by external information because it is considered to be selfrelevant. Hull et al. $(1988 ; 2002)$ argued that a state of high private self-focus activates selfknowledge, which instigates a process of self-relevant encoding. In line with this theorizing, we found that high self-focused people, as opposed to low self-focused people, were especially affected by external information that fits with their activated self-knowledge (in this case, their current orientation focus). Hence, when private self-focus is high, people are especially influenced by information that is congruent with their current orientation focus. 
Moreover, the present results shed new light on the concept of private self-focus. Previous research on private self-focus mainly has emphasized the self-regulatory process instigated by a state of private self-focus. This line of reasoning states that high private selffocus activates a self-regulatory process aimed at reducing discrepancies between one's current state and an internal norm or standard. In accordance with Hull and colleagues, we showed that a state of high private self-focus is related not only to discrepancy-reducing selfregulation but also entails a qualitatively different way of information processing aimed at rendering external information self-relevant.

This viewpoint is also consistent with the active-self account recently proposed by Wheeler, DeMarree, and Petty (2007). Wheeler and colleagues (2007) argue that the selfconcept plays a vital, central role in priming effects. According to their model, moderators of general priming effects, such as private self-focus (Hull et al., 2002), operate by more than simply affecting construct accessibility. Rather, changes in the active self-concept are key to how external information guides behavior. When external information is (actively) related to the self, as opposed to when it is not related to the self, it exhibits larger effects on behavioral outcomes because people use this information as a basis for evaluation and decision making. Accordingly, it is not merely awareness of oneself but rather the self-relevant information processing aspect of private self-focus (viz., high self-focused participants in the current studies) that explains the effects of external information on behavior. A recent study by Wheeler, Morrison, DeMarree, and Petty (2008) further argued that it is especially the selfreflective dimension, rather than the state awareness dimension, within the construct of private self-focus that accounts for the influence of external information on behavior under conditions of high private self-focus. 
It is perhaps paradoxical that the message of this research is that focusing people on themselves can lead them to respond more favorably to external persuasive attempts. One may think, a priori, that people who focus their attention on the environment, rather than themselves, would be highly compliant because they are aware of and therefore may be more susceptible to external information. Instead, we found the opposite. It was high private selffocused people who responded strongly to external persuasion attempts that match with their activated self-knowledge. This finding contrasts with the intuitive, possibly even cynical, notion that when people focus on themselves they become egocentric and therefore disinterested in information from the external environment, such as persuasive messages. The current work demonstrates that getting people to focus on themselves, in just the right circumstances, can pave the way to persuasion and behavioral compliance. 


\section{References}

Aaker, J. L., \& Lee, A. Y. (2001). 'I' seek pleasures and 'we' avoid pains: The role of selfregulatory goals in information. Journal of Consumer Research, 28, 33-49.

Avnet, T., \& Higgins, E. T. (2006). How regulatory fit affects value in consumer choices and opinions. Journal of Marketing Research, 43, 1-10.

Baumeister, R. F., Vohs, K. D., \& Funder, D. C. (2007). Psychology as the science of selfreports and finger movements: Whatever happened to actual behavior? Perspectives on Psychological Science, 2, 396 - 403.

Cesario, J., Grant, H., \& Higgins, E. T. (2004). Regulatory fit and persuasion: Transfer from 'feeling right'. Journal of Personality and Social Psychology, 86, 388-404.

Duval, S., \& Wicklund, R. A. (1972), A theory of objective self-awareness. New York: Academic Press.

Fenigstein, A., \& Levine, M. P. (1984). Self-attention, concept activation, and the causal self. Journal of Experimental Social Psychology, 20, 231-245.

Fenigstein, A., Scheier, M. F., \& Buss, A. H. (1975). Public and private self-consciousness: Assessment and theory. Journal of Consulting and Clinical Psychology, 43, 522-527.

Florack, A., \& Scarabis, M. (2006). How advertising claims affect brand preferences and category-brand associations: The role of regulatory fit. Psychology and Marketing, 23, $741-755$

Förster, J., Higgins, E. T., \& Chen Idson, L. (1998). Approach and avoidance strength during goal attainment: Regulatory focus and the 'goal looms larger' effect. Journal of Personality and Social Psychology, 75, 1115-1131.

Franzoi S. L., \& Brewer, L. C. (1984). The experience of self-awareness and its relation to level of self-consciousness: An experiential sampling study. Journal of Research in Personality, 18, 522-540. 
Fransen, M. L., Fennis, B. M., \& Pruyn, A. Th. H. (2007). Be all you can be: The influence of advertising slogans on regulatory focus and consumer spending behavior. In G. J. Fitzsimons \& V. G. Morwitz (Eds), Advances in Consumer Research, (pp. 206-207), Duluth, MN: Association for Consumer Research.

Geller, V., \& Shaver, P. (1976). Cognitive consequences of self-awareness. Journal of Experimental Social Psychology, 12, 99-108.

Higgins, E. T. (1997). Beyond pleasure and pain. American Psychologist, 52, 1280-1300.

Higgins, E. T. (2000). Making a good decision: Value from fit. American Psychologist, 11, 1217-1230.

Higgins, E. T. (2002). How self-regulation creates distinct values: The case of promotion and prevention decision making. Journal of Consumer Psychology, 12, 177-191

Higgins, E. T. (2005).Value from regulatory fit. Current directions in Psychological Science, $14,209-213$.

Higgins, E. T., Friedman, R. S., Harlow, R. E., Idson, L., Ayduk, O. N., \& Taylor, A. (2001). Achievement orientations from subjective histories of success: Promotion pride versus prevention pride. European Journal of Social Psychology, 31, 3-23.

Higgins, E. T., \& Tykocinski, O. (1992). Self-discrepancies and biographical memory: Personality and cognition at the level of psychological situation. Personality and Social Psychology Bulletin, 18, 527-535.

Hong, J., \& Lee, A . Y. (2008). Be fit and be strong: Mastering self-regulation through regulatory fit. Journal of Consumer Research, 34, 682-695.

Hull, J. G., \& Levy, A. S. (1979). The organizational functions of the self: An alternative to the Duval and Wicklund model of self-awareness. Journal of Personality and Social Psychology, 37, 756-768. 
Hull, J. G., Slone, L. B., Meteyer, K. B., \& Matthews, A. R. (2002). The nonconsciousness of self-consciousness. Journal of Personality and Social Psychology, 83, 406-424.

Hull, J. G., Treuren, R. R., Ashford, S. J., Propsom, P., \& Andrus, B. W. (1988). Selfconsciousness and the processing of self-relevant information. Journal of Personality and Social Psychology, 54, 452-465.

Idson, L., Liberman, N., \& Higgins, E. T. (2000). Distinguishing gains from nonlosses and losses from nongains: A regulatory focus perspective on hedonic intensity. Journal of Experimental Social Psychology, 36, 252-274.

Lee, A. Y., \& Aaker, J. L. (2004). Bringing the frame into focus: The influence of regulatory fit on processing fluency and persuasion. Journal of Personality \& Social Psychology, $86,205-218$

Mueller, J. H. (1982). Self-awareness and access to material rated as self-descriptive or nondescriptive. Bulletin of the Psychonomic Society, 19, 323-326.

Pham, M. T., \& Avnet, T. (2004). Ideals and oughts and the reliance on affect versus substance in persuasion. Journal of Consumer Research, 30, 503-518.

Scheier, M. F., \& Carver, C. S. (1983). Self-directed attention and the comparison of self with standards. Journal of Experimental Social Psychology, 19, 205-222.

Scheier, M. F., Carver, C. S., \& Gibbons, F. X. (1979). Self-directed attention, awareness of bodily states, and suggestibility. Journal of Personality and Social Psychology, 37, $1576-1588$.

Shah, J., Higgins, E. T., \& Friedman, R. S. (1998). Performance incentives and means: How regulatory focus influences goal attainment. Journal of Personality and Social Psychology, 74, 285-293.

Vleeming, R. G., \& Engelse, J. A. (1981). Assessment of private and public selfconsciousness: A Dutch replication. Journal of Personality Assessment, 45, 385-389. 
Wang, J. \& Lee, A. Y. (2006). The role of regulatory focus in preference construction. Journal of Marketing Research, 43, 28-38.

Wheeler, S. C., DeMarree, K. G., \& Petty, R. E. (2007).Understanding the role of the self in prime-to-behavior effects: The active-self account. Personality and Social Psychology Review, 11, 234-261.

Wheeler, S. C., Morrison, K. R., DeMarree, K. G., \& Petty, R. E. (2008). Does selfconsciousness increase or decrease priming effects? It depends. Journal of Experimental Social Psychology, 44, 882-889. 


\section{Figure Captions}

Figure 1. Helping behavior as a function of regulatory focus, message framing, and private self-focus.

Figure 2. Charity donations as a function of regulatory focus, message framing, and private self-focus. 
Figure 1.

Private Self-Focus: High

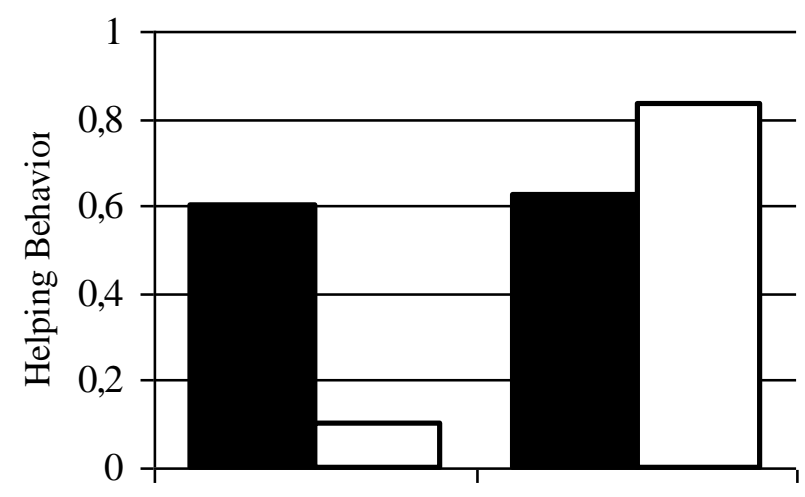

Focus: Promotion Focus: Prevention

Framing: Promotion $\square$ Framing: Prevention
Private Self-Focus: Low

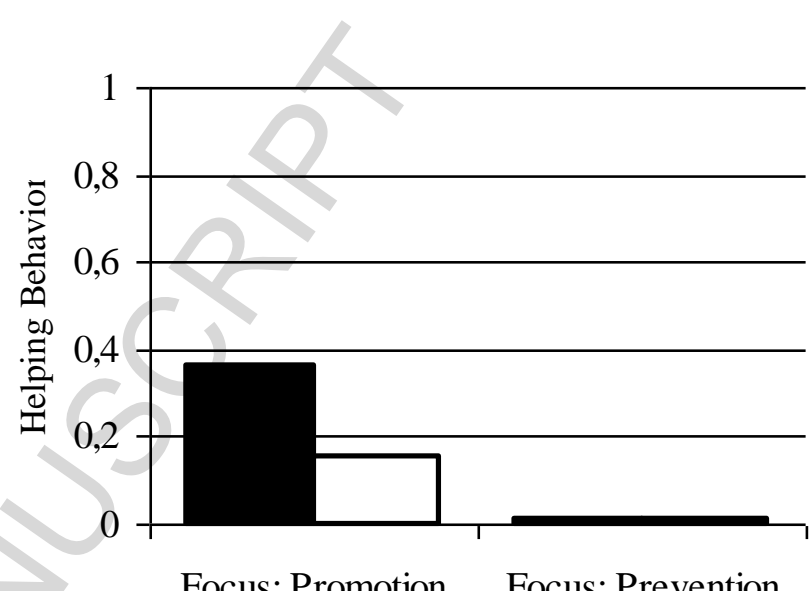

Framing: Promotion $\boldsymbol{\square}$ Framing: Prevention 
Figure 2.

Private Self-Focus: High

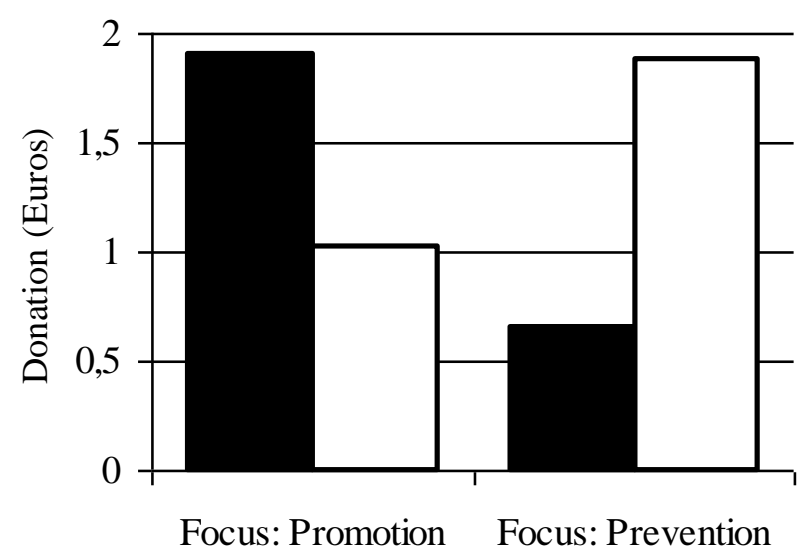

Framing: Promotion $\square$ Framing: Prevention
Private Self-Focus: Low

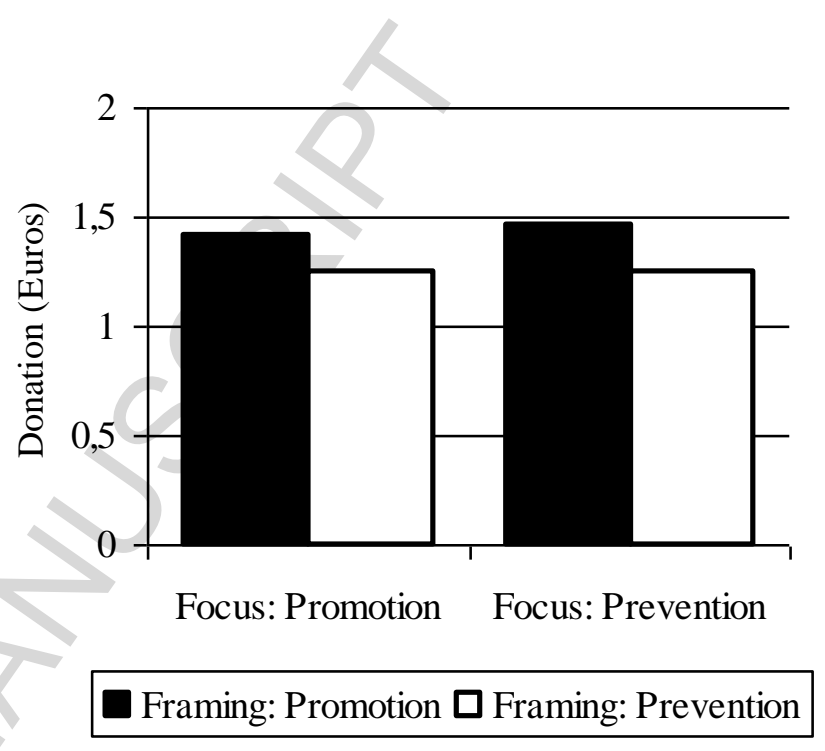

